\title{
Homogeneous Charge Compression Ignition (HCCI) Engines-A Review on the Technology for Posterity
}

\author{
V Akash \\ UG Student \\ Department of Mechanical Engineering \\ MIT Mysore
}

\author{
Ramanandan H S \\ Assistant Professor \\ Department of Mechanical Engineering \\ MIT Mysore
}

\begin{abstract}
For diesel engines. Fourth, optical diagnostics has been pplied widely to reveal in-cylinder combustion processes. HCCI combustion has been drawing the considerable attention due to high efficiency and lower nitrogen oxide (NOx) and particulate matter (PM) emissions. However, there are still tough challenges in the successful operation of HCCI engines, such as controlling the combustion phasing, extending the operating range, and high unburned hydrocarbon and CO emissions. Massive research throughout the world has led to great progress in the control of HCCI combustion.

The first thing paid attention to is that a great deal of fundamental theoretical research has been carried out. First, numerical simulation has become a good observation and a powerful tool to investigate HCCI and to develop control strategies for HCCI because of its greater flexibility and lower cost compared with engine experiments. Five types of models applied to HCCI engine modelling are discussed in the present paper. Second, HCCI can be applied to a variety of fuel types. Combustion phasing and operation range can be controlled by the modification of fuel characteristics. Third, it has been realized that advanced control strategies of fuel/air mixture are more important than simple homogeneous charge in the process of the controlling of HCCI combustion processes. The stratification strategy has the potential to extend the HCCI operation range to higher loads, and low temperature combustion (LTC) diluted by exhaust gas recirculation (EGR) has the potential to extend the operation range to high loads; even to full loads, In addition, the key to diesel-fuelled HCCI combustion control is mixture preparation, while EGR is the main path to achieve gasoline-fuelled HCCI combustion. Specific strategies for diesel- fuelled, gasoline-fuelled and other alternative fuelled HCCI combustion are also discussed in the present paper.
\end{abstract}

Keywords: CI, CO, HCCI, HC, NOx, PM, SI

\section{INTRODUCTION}

The internal combustion engine is one of the key drivers in modern industrial society. Without the transportation performed by the millions of vehicles, we would not have reached the living standard of today. There are two types of internal combustion engines: spark ignition (SI) and compression ignition (CI). The conventional SI combustion is characterised by a flame propagation process. The onset of combustion in SI engines can be controlled by varying ignition timing from the spark discharge.

Using a fixed air/fuel ratio means that the load controlling is possible only by controlling the air mass flow into the combustion chamber. The throttle used for this purpose gives rise to pumping losses and a reduction in efficiency. As a result, the major disadvantage of SI engines is its low efficiency at partial loads. In this type of engine, the air-fuel mixture auto-ignites as a consequence of piston compression instead of ignition by a spark plug. The processes which occur between the two moments when the liquid fuel leaves the injector nozzles and when the fuel starts to burn, are complex and include droplet formation, collisions, break-up, evaporation and vapour diffusion. For diesel engines, a trade-off between these two emissions is observed, and their problem is how to break through the compromise between NOx and PM emissions. After treatment to reduce NOx and particulates is expensive. Consequently, the obvious ideal combination would be to find an engine type with high efficiency of diesel engines and very low emissions of gasoline engines with catalytic converters. One such candidate is the process known as homogeneous charge compression ignition, HCCI, on which we shall now focus attention.

\section{HCCI Principle}

$\mathrm{HCCI}$ is characterised by the fact that the fuel and air are mixed before combustion starts and the mixture autoignites as a result of the temperature increase in the compression stroke. Thus HCCI is similar to SI in the sense that both engines use premixed charge and similar to $\mathrm{CI}$ as both rely on auto-ignition.

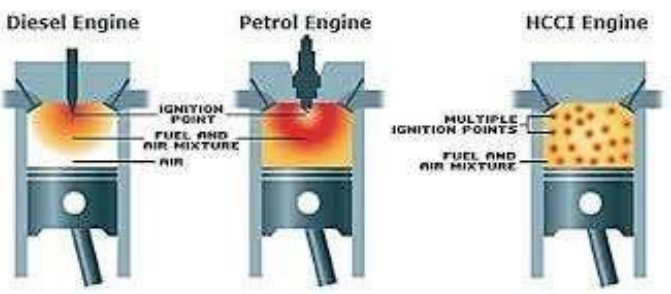

Fig: Principle of HCCI Engine

For gasoline-like fuels (high octane numbers), heat release from low temperature reaction (first-stage heat 
release) is less compared with diesel-like fuels at the same condition. Consequently, heat release from low temperature reaction is too little to obviously observe from the heat release profiles at most conditions for gasoline-like fuels. Research conducted with the use of optical diagnostics has shown that HCCI combustion initiates simultaneously at multiple sites within the combustion chamber and that there is no discernible flame propagation to initiate combustion.

\section{Research Developments on HCCI Technology}

The concept of HCCI was initially investigated for gasoline applications by Onishi et al. in order to increase combustion stability of two-stroke engines. They found that significant reductions in emissions and an improvement in fuel economy could be obtained by creating conditions that led to spontaneous ignition of the in-cylinder charge. Stable HCCI combustion could be achieved between low and high load limits with gasoline at a compression ratio of 7.5:1 over the engine speed range from 1000 to $4000 \mathrm{rpm}$. Noguchi et al. performed a spectroscopic analysis on HCCI combustion by experimental work on an opposed piston two stroke engine. From optical investigations they noted that ignition took place at numerous points throughout the cylinder and no discernible flame front was observed during combustion. Combined with the previous work of Onishi and Noguchi, it can be concluded that, unlike traditional SI combustion that relies on the flame propagation and diesel combustion that is heavily dependent on the fuel/air mixing, HCCI combustion is a chemical kinetic combustion process controlled by temperature, pressure, and composition of the in-cylinder charge.

Correspondingly, they noted that HCCI combustion suffers from a lack of control of the ignition process and a limited operating range. As discussed above, initial efforts with HCCI involved gasoline-fuelled engines, and this technology continues to be strongly pursued today. In many researches, gasoline-fuelled HCCI combustion is also called controlled auto-ignition (CAI) combustion. However, the need to reduce emissions from diesel engines led to investigation into the potential of dieselfuelled HCCI beginning in the mid-1990s. For diesel fuel, port fuel injection is perhaps the most straightforward approach to obtaining a pre-mixed charge and this approach has been used in some of the earlier investigations of diesel-fuelled HCCI. Ryan et al. used port fuel injection to supply diesel fuel into the intake air stream. An intake air heater upstream of the fuel injection point allowed preheating, with engine compression ratios varying between 7.5 and $17: 1$. This study and the following study on the same engine found: for diesel-fuelled HCCI, very premature ignition and knocking occurred using normal diesel compression ratios; relatively high intake temperatures were required to minimize the accumulation of liquid fuel on surfaces in the intake system; and unburned $\mathrm{HC}$ emissions tended to be very high, but NOx emissions were dramatically reduced. The results from these pioneering investigations indicate the strong potential of HCCI to improve thermal efficiency of gasoline- fuelled engines and substantially reduce NOx and soot emissions of diesel- fuelled engines. Furthermore, these results confirmed the dominating role of chemical kinetics in HCCI combustion, which has significance to following studies. However, they also foresaw some problems of this new combustion mode.

\section{Challenges of HCCI combustion}

Based on the pioneering research of HCCI combustion, obstacles that must be overcome before the potential benefits of HCCI combustion can be fully realized in production applications became clear with more and more studies. This section describes the main difficulties with this combustion mode:

a. The difficulty in combustion phasing control

One of the principal challenges of HCCI combustion is control of the combustion phasing. Unlike conventional combustion, a direct method for controlling the start of combustion is not available. Instead, the start of combustion is established by the auto-ignition chemistry of the air-fuel mixture. Auto-ignition of a fuel- oxidizer mixture is influenced by the properties of the mixture and by the time-temperature history to which it is exposed. Hence, combustion phasing of $\mathrm{HCCI}$ engines is affected by the following factors, autoignition properties of the fuel, fuel concentration, residual rate and, possibly, reactivity of the residual, mixture homogeneity, compression ratio, intake temperature, latent heat of vaporization of the fuel, and engine temperature, heat transfer to the engine and other engine-dependent parameters.

b. High levels of Noise, UHC and CO emissions

The second main challenge for HCCI operation is the potential increase in noise, UHC (unburned hydrocarbon) and $\mathrm{CO}$ emissions. As with all homogeneous combustion systems, a significant portion of the in-cylinder fuel is stored in crevices during the compression stroke and escapes combustion. Moreover, the burned gas temperature is too low to consume much of this unburned fuel when it re-enters the cylinder during the expansion stroke. This results in significant increase in both $\mathrm{HC}$ and $\mathrm{CO}$ emissions relative to conventional combustion. In addition, the peak burned gas temperatures are too low (lower than $1400 \mathrm{~K}$ or $1500 \mathrm{~K}$ ) to complete the $\mathrm{CO}$ to $\mathrm{CO} 2$ oxidation at low loads, and the combustion efficiency deteriorates precipitously. This loss of combustion efficiency combined with ignition difficulties limits the effectiveness of HCCI combustion at the lightest loads. At higher loads the rate of pressure rise can become so large that engine noise increases significantly, and if left unchecked, engine damage may occur.

c. Operation range

In addition to the above problems, another fundamental barrier in HCCI development is extending the operating 
load range whilst maintaining the full HCCI benefit. Extending the operating range is as important as the auto-ignition process. In addition to expanding the HCCI operation to higher load, very light load operation is also limited, because there is insufficient thermal energy to trigger auto-ignition of the mixture late in the compression stroke. Moreover, excess $\mathrm{CO}$ and $\mathrm{HC}$ emissions in combination with low exhaust gas temperature at near-idle operation makes this combustion mode less appealing from combustion efficiency and exhaust emissions perspectives.

\section{d. Cold start}

Since temperatures are very low at cold start operations and the heat loss from the compressed charge to the cold combustion chamber walls is so high, the HCCI engine will encounter a major difficulty in firing during cold start operation. To overcome this difficulty, the engine may have to be started in a conventional mode and then switched to the HCCI mode after a short warm-up period. Therefore, maintaining a real homogeneous combustion after cold start will also be a real challenge. HCCI operation for cold starts is an area where much more developmental effort is needed. Obviously, achieving a robust HCCI combustion at very light load with full HCCI benefits in fuel efficiency and emissions is as important as extending the HCCI operation to high loads.

\section{e. Homogeneous mixture preparation}

Effective mixture preparation and avoiding fuel/wall interactions is crucial for achieving high fuel efficiency, reducing $\mathrm{HC}$ and $\mathrm{PM}$ emissions, and preventing oil dilution. Fuel impinging on the surfaces of the combustion chamber has been proven disadvantageous to $\mathrm{HC}$ emissions even for moderately volatile fuels such as gasoline. Mixture homogeneity has an effect on auto- ignition reactions that control the HCCI combustion phasing, and there is significant evidence that low NOx emissions can be produced even with some degree of mixture inhomogeneity within the combustion chamber. Homogeneous mixture preparation is most difficult for fuels with reduced volatility such as diesel, which requires elevated intake air temperatures for low-smoke operation when portinjected.

\begin{tabular}{|l|l|l|}
\hline $\begin{array}{l}\text { Basis of } \\
\text { Comparison }\end{array}$ & SI Engine & $\begin{array}{l}\text { HCCI } \\
\text { Engine }\end{array}$ \\
\hline Efficiency & Less & More \\
\hline Throttle losses & More & No \\
\hline $\begin{array}{l}\text { Compression } \\
\text { ratio }\end{array}$ & Low & High \\
\hline Combustion duration & More & Less \\
\hline NOx emission & Comparatively low & Less \\
\hline
\end{tabular}

\begin{tabular}{|l|l|l|}
\hline $\begin{array}{l}\text { Basis of } \\
\text { Comparison }\end{array}$ & CI Engine & $\begin{array}{l}\text { HCCI } \\
\text { Engine }\end{array}$ \\
\hline Efficiency & High & $\begin{array}{l}\text { Equally } \\
\text { high }\end{array}$ \\
\hline Combustion temperature & $1900 \mathrm{~K}-2100 \mathrm{~K}$ & $\begin{array}{l}800 \mathrm{~K}- \\
1100 \mathrm{~K}\end{array}$ \\
\hline Cost & Comparatively high & Less \\
\hline Combustion duration & More & Less \\
\hline PM \& NOx emissions & More & Less \\
\hline
\end{tabular}

\section{ADVANTAGES}

The advantages of HCCI are numerous and depend on the combustion system to which it is compared. relative to SI gasoline engines, HCCI engines are more efficient approaching the efficiency of a CIDI engine. This improved efficiency, results from the three sources: the elimination of throttling loses, the use of high compression ratios, and a shorter combustion duration. HCCI engines also have lower engine-out NOx than SI engines. Although three-way catalyst is adequate for removing NOx from current technology SI engine exhaust, low NOx is an important advantage to spark ignition technology which is being considered for future SI engines.

Another advantage of HCCI engine combustion is its fuel flexibility. HCCI operation has been shown using a wide range of fuels. Gasoline is particularly well suited for HCCI operation. Highly efficient CI engines, on the other hand, cannot run on gasoline due to its low cetane number. HCCI engines might be commercialised in light duty passenger vehicles as much as to both half million barrels of oils per day may be saved.

HCCI is potentially applicable to both automobile and heavy truck engines. in fact, it could be scaled to virtually every size class of transportation engine from small motorcycle to large ships engines. HCCI is also applicable to piston engines used outside the transportation sector such as electrical power generation and pipe line pumping.

\section{RECENT DEVELOPMENTS IN HCCI}

Recent developments in HCCI technology has been given very positive results to overcome the limitations of this technology. The technology has huge scope of use and it is used in wide range of industries, which makes it a promising technology for the coming generations.

Automobile giants like GM, Ford, and Cummins have been exploring the possibilities in HCCI technology for more than a decade. GM has started educational programmes in various universities to promote the research work in this technology. HCCI has also enabled engineers to experiment with different blend of fuel mixtures so that performance and efficiency of HCCI engines can be tested with different combinations of non- conventional fuels.

GM has demonstrated Opel Vectra and Saturn Aura with modified HCCI engines. Mercedes-Benz has developed a prototype engine called Dies Otto, with controlled auto ignition.

In May 2008, GM gave Auto Express access to a Vauxhall Insignia prototype fitted with a 2.2 litre HCCI engine.

Cummins has been researching HCCI for almost 15 years. Industrial engines run in- house using HCCI combustion of natural gas achieved remarkable emission and efficiency results.

\section{CONCLUSION}

A high efficiency gasoline fuelled HCCI engine represents a major step beyond SI engines for light duty 
vehicles. The HCCI combustion engines have the potential to reduce the NOx and PM emissions simultaneously, while maintaining the thermal efficiency close to that of conventional diesel engine. But in HCCI combustion, many challenges have to be overcome such as difficulty in combustion planning control, misfire at low and knocking at high loads, cold start problems, difficulty in homogeneous mixture preparation, high rate of pressure rise and high level of noise, high level of $\mathrm{HC}$ and $\mathrm{CO}$ emissions.

\section{REFERENCES}

[1] Furutani M, Ohta Y, Komatsu K. Onset behaviour of lowtemperature flames caused by piston compression. JSAE Rev 1993;14(2):128.

[2] Pucher GR, Gardiner DP, Bardon MF, Battista V. Alternative combustion systems for piston engines involving homogeneous charge compression ignition concepts - a review of studies using methanol, gasoline and diesel fuel. SAE paper 962063 1996.

[3] Green RM, Cernansky NP, Pitz WJ, Westbrook CK. The role of low temperature chemistry in the auto-ignition on n-butane. SAE paper $872108 ; 1987$.

[4] Addargarla S, Henig Y, Wilk RD, Miller DL, Cernansky NP. Effect of fuel-air mixture stressing on pre-ignition heat release in a knock research engine. SAE paper 892082; 1989.

[5] Iida N. Combustion analysis of methanol-fueled active thermoatmosphere combustion (ATAC) engine using a spectroscopic observation. SAE paper $940684 ; 1994$.

[6] Aoyama T, Hattori Y, Mizuta J, Sato Y. An experimental study on premixed charge compression ignition gasoline engine. SAE paper $960081 ; 1996$.

[7] Onishi S, Jo SH, Shoda K, Jo PD, Kato S.Active thermoatmosphere combustion (ATAC) - a new combustion process for internal combustion engines. SAE paper 790501; 1979.

[8] Noguchi M, Tanaka T, Takeuchi Y. A study on gasoline engine combustion by observation of intermediate reactive products during combustion. SAE paper 790840; 1979.

[9] Najt PM, Foster DE. Compression ignited homogeneous charge combustion. SAE paper 830264; 1983.

[10] Thring RH. Homogeneous - charge compression ignition (HCCI) engines. SAE paper 892068; 1989.

[11] Ryan III TW, Callahan TJ. Homogeneous charge compression ignition of diesel fuel.SAE paper 961160; 1996.

[12] Gray III AW, Ryan III TW. Homogeneous charge compression ignition (HCCI) of diesel fuel. SAE paper 971676; 1997.

[13] Stanglmaier RH, Roberts CE. Homogeneous charge compression ignition (HCCI): benefits, compromise, and future engine applications. SAE paper 1999;01-3682; 1999.

[14] Dec JE.A computational study of the effects of low fuel loading. SAE paper 2002;01- 1309; 2002.

[15] Eng JA. Characterization of pressure waves in HCCI combustion. SAE paper 2002;01- 2859; 2002. 